\title{
MONOPOL U ISLAMSKOME PRAVU
}

\section{SAŽETAK}

Iako se oko pitanja monopola prenose hadisi u kojima Allahov Poslanik, s.a.v.s., osuđuje one koji vrše monopol, islamski pravnici su se razišli oko njegove definicije, kao i predmeta na što se monopol odnosi. I pored toga što se načelno razilaze oko pravnoga statusa monopola, svi se slažu da sakralni tekstovi (en-nusūs) koji se oko ovoga pitanju prenose, dovoljno ukazuju kako se radi o djelu kojega islam zabranjuje.

Da bi spriječili monopol, islamski pravnici predlažu određene mjere koje vlast treba da preduzme, kako bi se izbjeglo nanošenje bilo kakvoga oblika štete ljudima. Rad je obradio kaznu predviđenu za osobu koja vrši monopol, kao i mudrost zabrane monopola. Na kraju rada su spomenuti neki od savremenih oblika monopola.

Ključne riječi: islam, islamsko pravo, monopol, nepravda, šteta.

\section{Uvod}

Uzvišeni Allah je čovjeku potčinio Zemlju i sve na njoj, kako bi čovjek uživao u Božijim blagodatima i darovima. Međutim, neki ljudi su tu harmoniju narušili, pokušavajući da iskoriste određene okolnosti kako bi sebi priskrbili određenu materijalnu korist, zaboravljajući da time velikom broju ljudi nanose štetu, koju islam ne odobrava. O tome Uzvišeni Allah kaže: Allah je stvoritelj nebesa i Zemlje; On spušta s neba kišu i čini da pomoću nje rađaju plodovi kojima se hranite; $i$ daje vam da se koristite lađama koje plove morem voljom Njegovom, $i$ daje vam da se rijekama koristite; $i$ daje vam da se koristite Suncem $i$ Mjesecom, koji se stalno kreću, $i$ daje vam da se koristite noći $i$ danom; $i$ daje vam svega onoga što od Njega ištete, $i$ ako biste Allahove blagodati brojali, ne biste ih nabrojali. Čovjek je, uistinu, nepravedan i nezahvalan. (Ibrahim: 32-34)

\footnotetext{
${ }^{1}$ Islamski pedagoški fakultet u Bihaću
} 
Jedna od intencija islamskog zakonodavstva, jeste uklanjanje nepravde. Nepravda se dijeli na dva dijela: nepravda koju čovjek sebi nanosi griješenjem, nevjerovanjem i poricanjem, te nepravda koju ljudi nanose jedni drugima. Allahov Poslanik, s.a.v.s., je osudio svaku vrstu nepravde kada je rekao: Nema nanošenja štete a niti na štetu uzvratiti štetom (لَا ضَرَرَ وَلَا ضِرَرَارَ) Historija potvrđuje da je bilo među ljudima osoba koje su se uzoholile do te mjere, da su bile spremne da se poigravaju sa ljudskom sudbinom, kako bi stekle neku dunjalučku korist, zanemarujući štetu koju nanose drugima i posljedice koje će snositi na ovome i budućem svijetu. Upravo zbog toga, islamsko zakonodavstvo postavlja okvire i granice kojima sprječava nepravdu i realizira pravdu među ljudima. Jedna od manifestacija te nepravde, jesu i različiti oblici monopola. Putem monopola se nanosi šteta ljudima, a normalan i uobičajeni život postaje znatno otežan. S obzirom da islam osuđuje svaki oblik štete ili nepravde, samim tim zabranjuje pojedine vrste monopola. $\mathrm{U}$ jednome predanju Allahov Poslanik, s.a.v.s., kaže: Ko među muslimanima bude držao monopol nad hranom, Allah će ga kazniti gubom i bankrotom. ${ }^{3}$

Cilj ovoga rada je pojasniti stav islama spram monopola, koje su to vrste monopola zabranjene i pod kojim uslovima, te pojasniti pravni status monopola, predviđenu kaznu za osobe koje vrše monopol, kao i preventivne mjere za njegovo sprječavanje. Ova tema, prema mojim saznanjima, nije bila predmet istraživanja na našem podneblju, tako da će ovo biti jedan skroman doprinos izučavanju ove tematike. Posebno treba istaći nedostatak islamske literature koja govori o praktičnim primjerima slučajeva monopola u savremenom životu.

\section{Definicija monopola u islamskom pravu}

Mnoštvo je definicija koje precizno određuju pojam monopola $u$ islamskom pravu, a ja ću u ovome radu navesti tri:

\footnotetext{
${ }^{2}$ Bilježi ga Ibn-Madže (2340) od Ubade b. Samita, r. a.

${ }^{3}$ Bilježe ga Ibn-Madže (2155) i Ahmed (135) od Omera b. el-Hattaba, r. a.
} 
Alā'uddin el-Kāsān̄̄ ${ }^{4}$, autor djela Bedā'ius-sanā 'i je monopol u islamskome pravu definisao ovako: Kupovina hrane $u$ određenom mjestu i njeno neprodavanje koje šteti narodu ${ }^{5}$.

Autor djela Hanbelijske pravne škole Keššăful-kinā', Mensūr elBehūti $^{6}$ definirao je monopol na sljedeći način: Hrana koja se kupi za trgovanje, a zatim se skloni sa tržišta kako bi postala rijetka i skupa ${ }^{7}$.

Dakle, iz spomenute dvije definicije se da zaključiti da se monopol odnosi samo na hranu, koja se kupuje isključivo za trgovanje, te njeno sklanjanje sa tržišta dok ne postane rijetka na tržištu, a samim tim i njena tržišna cijena bude veća.

Međutim, malikijski pravnik Ed-Derdīri ovako definiše monopol: Praćenje tržišta u cilju iščekivanja povećanja cijena. ${ }^{8}$ Dakle, u ovoj definiciji se ne spominje hrana, nego se monopol odnosi na svaku vrstu robe.

\section{Šta sve može biti predmet monopola u islamskom pravu}

Islamski pravnici nisu jednoglasni oko pitanja šta sve može biti predmet monopola i oko tog pitanja razilaze se na tri mišljenja:

Prvi stav: Većina islamskih učenjaka (džumhūr) smatra da predmet monopola može biti isključivo hrana. ${ }^{9}$

Drugi stav: Malikijska pravna škola i Ebu-Jusuf ${ }^{10}$ iz Hanefijske, smatraju da se zabranjeni monopol odnosi na sve što može da šteti

\footnotetext{
${ }^{4}$ Alā'uddin el-Kāsānī (587. H.), čuveni islamski pravnik hanefijske pravne škole i autor djela Bedā 'ius-sanā' $i$.

5 El-Kāsānī Alā'uddin, Bedā'ius-sanā'i, Dār ihjā’ et-turas el-arebi, Bejrut, 1997. prvo izdanje, str. 4., 308.

${ }^{6}$ Mensūr el-Behūti (1051. H.), čuveni islamski pravnik Hanbelijske pravne škole i autor djela Keššăful-kinā':

${ }^{7}$ El-Behūti Mensūr, Keššāful-kinā', Dārul-fikr, Bejrut, 1402. H., str. 3, 187.

${ }^{8}$ El-Mevsū'atul-fikhijje, Ministarstvo za vakufe i islamska pitanja, Kuvajt, 1983., Drugo izdanje, str. 2., 90.

${ }^{9}$ o. c., str. 2., 92.

${ }^{10}$ Ebu-Jusuf: Ime mu je Jakub b. Ibrahim, ali je poznatiji kao Ebu-Jusuf. Rođen je 113. hidžretske godine u Kūfi, a na bolji svijet je preselio 182. H. Prvi je EbuHanifin učenik koji je napisao islamskopravno djelo prema hanefijskoj pravnoj školi. Iako se po određenim pitanjima osamostalio, smatra se najzaslužnijim za širenje hanefijske pravne škole, s obzirom da je prvi Glavni kadija u historiji
} 
ljudima, te da se pod hadisima koji govore o zabrani monopola misli, upravo, na sve što šteti ljudima. ${ }^{11}$

Treći stav: Muhammed b. el-Hasen eš-Šejbāni ${ }^{12}$, pravnik Hanefijske pravne škole, smatra da predmet monopola može biti isključivo hrana za ljude i životinje. ${ }^{13}$

\section{Argumenti:}

Svako od ova tri mišljenja ima svoje argumente i obrazloženja radi kojih su se za njih opredijelili.

Argumenti učenjaka koji zastupaju prvi stav:

a) Hadis: Ko bude držao monopol nad hranom četrdeset noći, taj se odrekao od Allaha i Allah se odrekao od njega. ${ }^{14}$

b) Hadis: Ko među muslimanima bude držao monopol nad hranom, Allah će ga kazniti gubom i bankrotom. ${ }^{15}$ Dakle, svi hadisi koji se oko ovog pitanja navode spominju hranu, što eksplicitno ukazuje da se odnose, isključivo, na hranu.

Argumenti učenjaka koji zastupaju drugi stav:

Značajan dio hadisa koji govore o zabrani monopola ne spominju hranu, što ukazuje da se podrazumijeva sve što kod ljudi može izazvati poteškoće, zato što se tadašnji način života ograničavao na principu trampe, a najčešći predmet trampe bila je hrana.

Argumenti učenjaka koji zastupaju treći stav:

Koristili su identične argumente učenjaka koji zagovaraju prvo mišljenje, s tim da su analogno hrani za čovjeka dodali i hranu za

islamske države za vrijeme halife Haruna er-Rešida. Iza sebe je ostavio nekoliko djela od kojih je najpoznatija El-Harādž.

${ }^{11}$ Zejn b. Ibrahim b. Muhammed, El-Bahrur-rā'ik, Dārul-ma'rife, Bejrut, str. 8., 229; El-Magribi, Muhammed b. Abdur-rahman, Mevāhibul-Dželīl, Dārul-fikr, 1398., H., drugo izdanje, str. 4., 227.

${ }^{12}$ Muhammed b. el-Hasen eš-Šejbāni: Rođen je 132. hidžretske godine u Kūfi. Islamskopravnu nauku je uzeo od Ebu-Hanife, ali je nakon imamove smrti imao kontakata i rasprava sa Evza'ijem i Šafijom. Najzaslužniji je za kodificiranje hanefijske pravne škole, a iza sebe je ostavio šest djela i predanje Malikove Muvette.

${ }^{13}$ El-Kāsānī Alā’uddin, Bedā 'ius-sanā 'i, str. 4., 308.

${ }^{14}$ Bilježi ga Ahmed (4648) od Abdullaha b. Omera, r. a.

${ }^{15}$ Bilježe ga Ibn-Madže (2155) i Ahmed (135) od Omera b. el-Hattaba, r. a. 
životinje, jer su i one stvorenja kojima je uskraćivanje hrane, također, nanošenje štete.

\section{Rasprava i odabrano mišljenje}

Islamski pravnici se u globalu slažu oko pravila, da ako se desi šteta da se uklanja, te su na osnovu toga otvorili raspravu o tome šta sve može biti predmet monopola $u$ islamskome pravu. Jasno je da bi nedostatak određenih stvari, mimo hrane za ljude i životinje, prouzrokovao ogromno i očigledno opterećenje za ljudski rod. Kao primjer možemo navesti nedostatak ili potpuni nestanak električne energije ili nafte, bez kojih bi život savremenog čovjeka bio težak i skoro neizdržljiv. Monopol na ovim i sličnim stvarima značio bi paraliziranost ljudskoga života na svijetu. Istina, ove dvije stvari ne ugrožavaju biološki opstanak čovjeka, ali bi ljudski život u velikoj mjeri bio otežan. Prema tome, mišljenja koje zagovaraju većina islamskih pravnika i imam Muhammed, kako predmet zabranjenog monopola može biti isključivo hrana za ljude i životinje, može se oboriti činjenicom da bi monopol nad pojedinim resursima, poput nafte, prouzrokovao ogromnu štetu, kako pojedincima tako i državama.

Argumenti da se hadisi koji zabranjuju monopol odnose isključivo na hranu, mogu se razumjeti na način da je hrana u vremenu izricanja hadisa bila najčešća trgovačka roba, te se stoga argumenti koji monopol ograničavaju na hranu, mogu u tome kontekstu i razumjeti.

Ljudske potrebe se $\mathrm{u}$ islamskom pravu dijele na tri vrste: neophodne (ar. darūrijāt), potrebne ( hādž̄jāt) i luksuzne (kemālijāt). $\mathrm{S}$ obzirom na razvoj ljudskog života na zemlji, mnoge stvari koje su spadale u potrebne (hâdžijāt), vremenom i razvojem savremenog života su prerasle u neophodne (darūrijāt). Dakle, ukoliko želimo da pomirimo argumente i stavove, onda možemo konstatirati kako se zabranjeni monopol odnosi na neophodne (darūrijāt) i potrebne ( $h \bar{a} d z ̌ i j a \bar{t}$ ) stvari, iako je malikijsko mišljenje i mišljenje Ebu-Jusufa, r. a., obuhvatnije, pošto štiti interese običnog čovjeka i eliminira moguću štetu koja bi mu se mogla dogoditi. 


\section{Odabrano mišljenje}

Nakon navođenja mišljenja islamskih pravnika i njihovih argumenata, te nakon njihovoga analiziranja, možemo konstatirati da je najbliže mišljenje intencijama islamskoga zakonodavstva ono koje smatra, da se zabranjeni monopol odnosi na sve ono čije uskraćivanje predstavlja štetu ljudima. U obrazloženju opredjeljenja za ovaj stav, možemo navesti da duh i intencije islamskoga prava imaju za cilj da uklone i eliminiraju svaku moguću štetu koja bi mogla pogoditi ljude, te da olakšaju ljudski život, a zasigurno bi ograničavanje zabranjenog monopola na ljudsku i životinjsku hranu, prouzrokovalo veliku štetu ljudskome rodu. A Allah najbolje zna!

\section{Pravni status monopola u islamskom pravu}

Većina islamskih pravnika smatra kako je pravni status monopola izričita zabrana, tj. haram, radi nepravde i štete koja se preko monopola nanosi ljudima. ${ }^{16}$

Međutim, jedan broj šafijskih učenjaka smatra da je monopol pokuđen, tj. mekrūh, dok su se hanefijski pravnici razišli na dva pravca - jedni smatraju da ima status mehrūh-tahrīmen, dok imam Kāsānī smatra da je izričito zabranjen, tj. haram. ${ }^{17}$ Neki islamski autoriteti su otišli korak dalje i smatraju kako monopol spada u najveće grijehe (kebā'ir), poput Ibn-Hadžera el-Hejtemija ${ }^{18}$. On u svom djelu Ez-Zevādžir, nakon što je naveo argumente koji aludiraju na zabranu monopola, kaže sljedeće: Iz ovih vjerodostojnih hadisa je očigledno da se ovo može ubrojati u velike grijehe, jer neki od njih sadrže žestoku prijetnju, poput prokletstva $i$ odricanja Allaha $i$ Poslanika od osobe koja vrši monopol, te kažnjavanja gubom $i$ bankrotom, a svaki od njih aludiraju da se radi o jednome od najvećih grijeha. ${ }^{19}$

\footnotetext{
${ }^{16}$ El-Mevsū 'atul-fikhijje, str. II, 90.

${ }^{17}$ El-Kāsānī Alā'uddin, Bedā 'ius-sanā ‘i, str. 4., 309.

${ }^{18}$ Ibn-Hadžer el-Hejtemi (974. H.), Ahmed b. Muhammed, čuveni pravnik Šafijske pravne škole. Autor je velikog broja naslova.

${ }^{19}$ El-Hejtemi Ibn-Hadžer, Ez-Zevādžir, El-Mektebetul-'asrijje, Bejrut, 1999., Drugo izdanje, str. 1., 451-453.
} 
U svakome slučaju, svi se slažu da postoji zabrana za osobu koja vrši monopol. Sagledavajući njihove argument, možemo dati prednost prvome mišljenju koje zagovara da je pravni status monopola izričita zabrana, a što se tiče druga dva mišljenja, može se konstatirati da mišljenje pojedinih šafijskih pravnika nije oficijelan stav njihove pravne škole, te da su se hanefijski pravnici razišli s obzirom na njihovu podjelu između harama i mekrūha-tahrīmena, pošto oni prave razliku oko pitanja autentičnosti dokaza.

Razlozi preferiranja ovoga mišljenja su sljedeći: šteta koju prouzrokuje monopol, hadisi koji u sebi sadrže žestoku prijetnju, te predanja koja govore o ahiretskoj kazni za osobu koja se bavi monopolom. U tom kontekstu su i riječi hanefijskog pravnika imama Kāsānija ${ }^{20}$, koji je rekao: Kletva se odnosi isključivo na postupak koji ima status harama. $^{21}$

\section{Uvjeti zabranjenog monopola}

Da bi se monopol smatrao zabranjenim, islamski pravnici su postavili nekoliko uvjeta, a to su:

1. Da se predmet monopola dobije preko kupoprodaje, a ne na drugi način preko uzgajanja ili roda, iako se s ovim ne slažu pojedini malikijski pravnici i Ebu-Jusuf, jer smatraju da je poenta u šteti, a nikako u činjenici da je roba kupljena ili ne;

2. Da se monopol vrši u stanju opće potrebe za tom robom, jer se monopol u prirodnim okolnostima ne smatra izričito zabranjenim, iako pojedini islamski pravnici ovaj uvjet ne smatraju validnim;

3. Da roba bude kupljenja u vrijeme skupoće i krize. To zagovaraju samo pravnici Šafijske pravne škole;

20 El-Kāsāni Alauddin (587. H.) čuveni hanefijski pravnik. Porijeklom je iz Turkistana, ali je značajan dio života proveo u Halepu i Damasku (Sirija). Najpoznatije njegovo djelo je Bedai'us-sana' $i$ koje predstavlja komentar djela EtTuhfe od Alauddina es-Semerkandija, koji ga je, kao nagradu za komentar, oženio svojom kćerkom Fatimom.

${ }^{21}$ El-Kāsān̄̄ Alā'uddin, Bedā 'ius-sanā' ‘i, str. 4., 309. 
4. Da roba bude kupljena unutar grada ili države ${ }^{22}$, jer se monopol ne smatra zabranjenim ukoliko je roba uvezena izvan granica države, iako se s tim ne slažu hanefijski pravnici Ebu-Jusuf i Muhammed, što je bliže savremenim prilikama, pošto se savremena ekonomija, općenito, u velikoj mjeri oslanja na uvoz;

5. Da osoba koja vrši monopol ima namjeru, da skloni robu sa tržišta kako bi njena vrijednost porasla. ${ }^{23}$

\section{Period zabranjenog monopola}

Islamski učenjaci se razilaze oko uvjetovanja perioda kako bi se monopol smatrao zabranjenim. Prvi smatraju da se period ne uslovljava, jer je poenta $u$ šteti i nepravdi koje se nanose, a ne $u$ periodu, kao i zbog činjenice da hadisi koji govore o monopolu ne spominju nikakav period.

Oni koji smatraju da se period uvjetuje, razišli su se oko njegovog trajanja:

1. Jedni smatraju da se ostavlja običaju ili šteti koju prouzrokuje;

2. Drugi da traje mjesec dana;

3. Treći da traje četrdeset dana, jer se u jednoj od predaja navodi:

Ko vrši monopol nad hranom četrdeset noći, on se odrekao Allaha i Allah se odrekao njega. ${ }^{24}$

\section{Kazna za osobu koja vrši monopol}

Islamski učenjaci su kaznu koja se odnosi na osobu koja vrši monopol podijelili na:

1. Dunjalučku - slažu se kako vlast treba narediti osobi koja vrši monopol da robu iznese na tržište $\mathrm{i}$ da je proda po razumnim cijenama, kao i da u slučaju da će zasigurno nanijeti štetu građanstvu, vlast ima obavezu da ga privoli da proda robu. Međutim, razišli su se

\footnotetext{
22 Slučaj kada je trgovina bila u velikoj mjeri ograničena. Danas, u savremenim prilikama, je to nezamislivo s obzirom da se trgovina u najvećoj mjeri oslanja na uvoz, tako da je mišljenje Ebu-Jusufa i Muhammeda bliže savremenim prilikama.

${ }^{23}$ El-Mevsū' 'atul-fikhijje, str. 2., 93-94.

${ }^{24}$ Bilježi ga Ahmed (4648) od Abdullaha b. Omera, r. a.
} 
oko pitanja ukoliko zasigurno ne predstavlja štetu za građanstvo. Jedan od vidova dunjalučke kazne, jeste i to što se spominje u hadisu da ko među muslimanima bude držao monopol nad hranom, Allah će ga kazniti gubom i bankrotom;

2. Ahiretsku - u hadisima koji spominju monopol, nalazimo da osobu koja vrši zabranjeni monopol čeka nekoliko kazni, a to su: Allahovo odricanje od te osobe, Allahovo prokletstvo i džehennemska vatra.

\section{Mudrost zabrane monopola}

Iz islamske zabrane monopola možemo crpiti sljedeće mudrosti:

1. Jedna od osnovnih intencija islama jeste uklanjanje nepravde $i$ uspostava pravde među ljudima, a zasigurno zabrana monopola osigurava preduvjete za takvo što;

2. Uklanjanje neprijateljstva i mržnje među ljudima, jer monopol proizvodi jednu vrstu ovakvih odnosa u društvu, s obzirom da se kod osobe nad kojom se vrši monopol, kroz gorčinu nepravde, javlja izražen osjećaj mržnje prema osobi koja ga iskorištava;

3. Zabrana monopola je prepreka stvaranju različitih društvenih slojeva, jer monopol stvara neravnopravne slojeve u društvu, koji se međusobno mrze, sukobljavaju i bore za prevlast, te posebno treba istaći činjenicu da gasi svaki osjećaj vjerskog bratstva kojega islam proklamuje;

4. Monopol je jedan od vidova zabranjenog načina poslovanja i pribavljanja koristi i zarade, s obzirom da se bazira na iskorištavanju otežavajućih okolnosti i ekonomskih kriza, pri čemu se nanosi šteta običnim građanima.

\section{Primjeri savremene primjene monopola:}

Prije nego što navedemo savremene primjere monopola, navest ćemo nekoliko primjera koje su spomenuli klasični islamski pravnici, a to su:

Prvo: Monopol nad poslom. Tu spada zabrana nosačima (hamalima) i pogrebnim društvima da se udružuju, jer bi to značilo da 
će se cijene tih usluga povećati. O tome islamski autoritet IbnulKajjim el-Dževzijje ${ }^{25}$ kaže sljedeće: Vlasti trebaju zabraniti pogrebnim društvima i nosačima (hamalima) da se udružuju, jer se na taj način povećavaju cijene njihovih usluga. To se odnosi i na svaku drugu struku čije su usluge potrebne ljudima, poput svjedoka, vodiča $i$ $d r{ }^{26}$

Drugo: Monopol esnafa. Radi se o praksi da se roba prodaje samo određenim trgovcima, koji imaju monopol nad prodajom iste. $\mathrm{U}$ slučaju da to uradi neko mimo njih, zaslužio bi kaznu i to bi mu bilo zabranjeno, što je nedvojbeno neprihvatljiva nepravda. ${ }^{27}$

Kada su u pitanju savremeni primjeri primjene monopola, tu možemo navesti nekoliko primjera ${ }^{28}$ :

1) Monopol vlasti

Ovo je pitanje novijeg datuma, jer je država nekada bila jednostavnije organizirana, s obzirom da se počelo postavljati tek nakon savremenoga uređenja država, gdje vlast ima mogućnost da sama eksploatira prirodna dobra svojih teritorija, ili da to prepusti privatnicima, uz odgovarajuću nadoknadu, pri čemu se rukovodi činjenicom da odabire ono što je više u interesu naroda. Ova je vrsta monopola zabranjena, kao što je slučaj sa monopolom esnafa i firmi. Također, isti pravni status ima monopol, koji ide u korist pojedinih trgovaca i pojedinaca, ili za vršenja pritiska vlasti nad građanima.

Međutim, ukoliko je taj monopol u interesu naroda, u tom slučaju je, bez sumnje, ovakav vid monopola dozvoljen. ${ }^{29}$

2) Monopol jedne države nad drugom

Kada je u pitanju monopol nad izvozom iz jedne države u drugu, tu se može kazati sljedeće:

\footnotetext{
${ }^{25}$ Ibnul-Kajjim el-Dževzijje (751. H.g.), hanbelijski pravnik i učenik Ibn-Tejmijje, autor mnogobrojnih djela od kojih je najpoznatije $Z \bar{a} d u l-m e$ ' $\bar{a} d$.

${ }^{26}$ Ibnul-Kajjim el-Dževzijje, Et-Turukul-hukmijje, Dāru 'ālemul-fevāid, Džedda, str. II, 642 .

${ }^{27}$ Ibid., str. II, 640.

28 Šemsuddin Mehdi, El-Ihktikār fiš-šerīatil-islamijje, El-Muessesetud-devlijje, Bejrut, 1998., drugo izdanje, str. 256-252.

${ }^{29}$ Ibid., str. 274-275.
} 
- Ukoliko država ne posjeduje višak robe za prodaju, u tom slučaju je monopol, bez sumnje, dozvoljen;

- Ukoliko država posjeduje višak, ali vrši monopol nad robom u cilju dobivanja određenih povlastica ili radi pritisaka na drugu zemlju, u tom slučaju je monopol nad tom robom zabranjen. ${ }^{30}$

Savremena globalna kretanja, nažalost, nameću monopol najvećih svjetskih sila nad svim robama, tako da zemlje u razvoju ostaju bez realnih prilika za ekonomski napredak, jer su šanse ekonomskog nadmetanja svedene na minimum, a sve to kroz razne oblike monopola od strane najvećih ekonomskih sila.

\section{Preventivne mjere za borbu protiv zabranjenog monopola}

Prije svega, važno je napomenuti da država ima pravo da preduzme bilo kakve mjere, koje štite interese države i građana, oslanjajući se na princip šerijatske politike (es-sijāse ěs-šer 'ijje), kako bi zabranila nanošenje štete ljudima. Međutim, islamski pravnici su predložili neke od mjera i koraka koje država može preduzeti u cilju zabrane monopola, a te mjere su:

1. Zabrana presretanja trgovačke robe (telekkir-rukbān) ili prodaja proizvoda nomada osobi koja boravi u nekom mjestu (bej'ulhâdiri lil-bād $)$, a koje su utemeljene sunnetom, kao što je hadis u kojem Allahov Poslanik, s.a.v.s., kaže: Ne predusrećite karavandžije i neka onaj koji boravi u nekom mjestu ne prodaje proizvode nomada; ${ }^{31}$

2. Uvođenje zakonskih propisa, koji sprječavaju zabranjeni monopol, poput:

- Obavezivanje osobe koja vrši monopol da proda robu za razumne i normalne cijene;

- Nametanje cijene od strane vlasti (tes ‘’ir), kako bi se izbjeglo poigravanje s cijenama na tržištu, iako se islamski pravnici razilaze oko njegove dozvoljenosti;

\footnotetext{
${ }^{30}$ Ibid., str. 278-279.

${ }^{31}$ Bilježe ga Buharija (2158) i Muslim (1521) od Ibn-Abbasa, r.a.
} 
- Kažnjavanje osobe koja vrši monopol, a te se kazne kreću između upozorenja, pa sve do naredbe da proda robu po razumnim cijenama, ali i do odgovarajućih mjera, poput izricanja mjere novčane kazne ili privremenog pritvora.

\section{Zaključak}

Na kraju ovoga rada možemo konstatovati sljedeće:

Islamski pravnici se slažu da je monopol koji šteti ljudima zabranjen, s tim što se razilaze oko pitanja na šta se sve može odnositi, iako sam lično preferirao mišljenje da svaka roba $\mathrm{s}$ čijim manipuliranjem se nanosi šteta ljudima, ima status zabranjenog monopola;

1. Iako se u izrekama Allahovoga Poslanika, s.a.v.s., monopol osuđuje, ipak se monopol, prema većini islamskih pravnika, smatra zabranjenim samo ukoliko se vrši u vrijeme velikih poskupljenja i oskudica;

2. Islamski pravnici su predvidjeli odgovarajuće preventivne i kaznene mjere, kako ne bi došlo do monopola iz kojega proizlazi šteta ljudima;

3. Velik broj hadisa koji osuđuju štetni monopol najbolje ukazuje na pogubnost ovoga postupka, te da osobe koje ga čine čeka velika dunjalučka i ahiretska kazna;

4. Tradicionalni islamski pravnici su pitanje monopola istraživali u uskim okvirima sakralnih tekstova koji se oko tog pitanja prenose i okolnostima u kojima su živjeli, tako da je istraživanje ove teme u velikoj mjeri ostalo ograničeno vremenskim i svim drugim okvirima osoba koje su ga istraživale.

\section{Literatura:}

1. Ahmed b. Hanbel, Musned, Bejtul-efkar ed-devlijje, Rijad, 1998.

2. El-Behūti Mensūr, Keššăful-kinā', Dārul-fikr, Bejrut, 1402. H.

3. El-Hejtemi Ibn-Hadžer, Ez-Zevādžir, El-Mektebetul-'asrijje, Bejrut, 1999., Drugo izdanje.

4. El-Kāsānī Alā'uddin, Bedā 'ius-sanā 'i, Dār ihjā' et-turas el-arebi, Bejrut, 1997., Prvo izdanje 
5. El-Magribi, Muhammed b. Abdur-rahman, Mevāhibul-Dželīl, Dārul-fikr, 1398., H., Drugo izdanje.

6. El-Mevsū'atul-fikhijje, Ministarstvo za vakufe i islamska pitanja, Kuvajt, 1983., Drugo izdanje.

7. Ibn-Madže el-Kazvīnī, Sunen Ibn-Madže, Dār ihjā’ el-kutub el-arebijje.

8. Ibnul-Kajjim el-Dževzijje, Et-Turukul-hukmijje, Dāru 'ālemul-fevāid, Džedda.

9. Kur'an

10. Muhammed b. Ismail el-Buhari, Sahīhul-Buhari, Dāru Ibn-Kes̄ir, Damask, 2002., Prvo izdanje.

11. Muslim b. Hadžādž, Sah̄̄h Muslim, Dārul-mugni, Rijad, 1998., Prvo izdanje.

12. Šemsuddin Mehdi, El-Ihktikār fiš-šerīatil-islamijje, El-Muessesetud-devlijje, Bejrut, 1998., Drugo izdanje.

13. Zejn b. Ibrahim b. Muhammed, El-Bahrur-rā'ik, Dārul-ma'rife, Bejrut. 
HAJRUDIN HODŽIĆ, M.A.

\section{MONOPOLY IN ISLAMIC JURISPRUDENCE}

\section{SUMMARY}

Although there are Hadith transmitted regarding status of monopoly in which Allah's Messenger, p.b.u.h., condemns those who practice it, Islamic jurists have disagreed regarding the definition of monopoly, and its main subject.

Despite a formal disagreement regarding the juristic status of monopoly, all Islamic jurists agree that sacral texts (Arabic An-nusus) provide sufficient evidence to state that Islam prohibits this act.

In order to prevent monopoly, Islamic jurists suggest certain measures which authorities need to undertake to avoid afflicting any form of damage to the people. This paper, has also elaborated sentence intended for a person who practises monopoly, and wisdom which is found in its prohibition. Some of the modern forms of monopoly are mentioned in the concluding part of this paper.

Key words: monopoly, Islam, Islamic jurisprudence, damage, injustice 


$$
\text { الأستاذ خيرالدين هوجيتش }
$$

\section{الاحتكار في الشريعة الإسلامية}

\section{خلاصة البحث}

على الرغم من أنه وردت في مسألة الاحتكار الأحاديث عن رسول الله صلى الله عليه وسلم التي تنكر على المحتكرين، إلا أن الفقهاء يختلفون حول تعريف الاحتكار وموضوعه. وعلى تهن الرغم من أفم يختلفون حول حكم الاحتكار الشرعي، إلا أفم يتفقون على أن النصوص الواردة

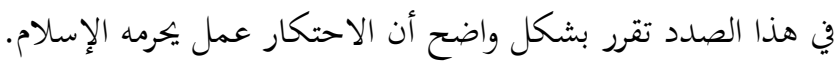

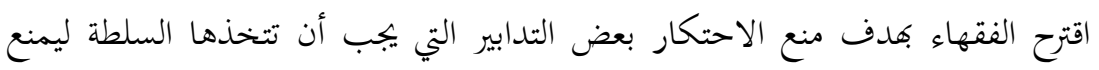

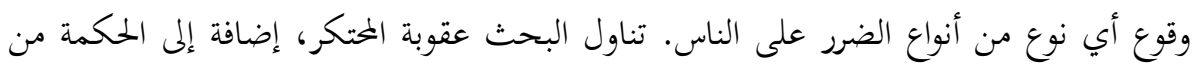
تحريم الاحتكار. في فاية البحث ذكرت بعض صور الاحتكار المعاصرة. الكلمات الرئيسة: الاحتكار، الإسلام، الشريعة الإسلامية، الضرر، الظلم 